\title{
Fertility Preservation Options for Cancer Patients
}

\author{
Murid Javed, Essam Michael \\ Astra Fertility Clinic, Mississauga, Canada \\ Email: murid.javed@astrafertility.com \\ Received 11 August 2015; accepted 1 November 2015; published 5 November 2015 \\ Copyright (C) 2015 by authors and Scientific Research Publishing Inc. \\ This work is licensed under the Creative Commons Attribution International License (CC BY). \\ http://creativecommons.org/licenses/by/4.0/

c) (†) Open Access

\begin{abstract}
The number of reported new cancer cases is increasing every year. The probability of surviving cancer is high and is continually improving. The cancer treatment may induce ovarian or testicular failure by damaging ovarian follicles in females and spermatogonia in the males. Gonadal failure may affect all aspects of reproductive health, including pubertal development, hormone production, and sexual function in adult life. Therefore, the primary goal for cancer treatment is to ensure the highest possibility of cure and to maintain the reproductive health. The cancer patients should be provided with maximal chance to make an optimal decision without any significant impact and delay in cancer treatment. As a result of treatment innovations, the survival rates of young people have increased substantially; therefore, the need of fertility preservation has increased as well. The sperm cryopreservation and embryo cryopreservation have been standard methods of fertility preservation. Recently, the American Society for Reproductive Medicine has removed the experimental label from oocyte cryopreservation. However, other fertility preservation options including ovarian tissue and whole ovary cryopreservation and testicular tissue cryopreservation for pre-pubertal boys are still considered experimental. A coordinated approach by gynecologists, urologists, oncologists, pediatricians, surgeons, fertility specialists and counselors is required to make use of available fertility preservation options. Timely and complete information on the impact of cancer treatment on fertility and fertility preservation options should be presented to all patients when a cancer treatment is planned. The possibility of fertility preservation removes a huge concern and enables cancer patients to concentrate on their treatment and getting better. The purpose of this review is to present different options currently available to preserve fertility in men, women and adolescent children diagnosed with cancer and undergoing gonadotoxic therapy. All options are listed in two tables for quick reference. Most of the information is extracted from recent publications and presented in such a manner that it is valuable for cancer patients and professionals associated with fertility preservation.
\end{abstract}

\section{Keywords}

Fertility Preservation, Oocyte Cryopreservation, Sperm Cryopreservation, Ovarian Tissue, Cancer 


\section{Introduction}

Cancer spares no age group and loss of fertility is a major concern for patients after cancer treatment. Gonadal failure especially in young age may affect all aspects of reproductive health, including pubertal development, hormone production, and sexual function in adults. With advancement in cancer treatment, the probability of surviving cancer is high and is continually improving [1]; thus, the need for fertility preservation in all age groups including adolescent boys or girls has increased. The fertility counselling on individual basis is highly required and is greatly valued by cancer patients because it gives them a choice about future fertility. The fertility expert can present various fertility preserving scenarios and the patients are content that there is an actual choice and it contributes to a belief in their own survival [2].

Currently sperm banking, regardless of the source (ejaculated, epididymal or testicular) and embryo banking are the standard methods to preserve fertility for cancer patients [3]. Ejaculated sperm can subsequently be used for intra-uterine insemination, in vitro fertilization (IVF) using egg insemination or intracytoplasmic sperm injection (ICSI) depending on the sperm concentration and motility after cryopreservation and thaw. Epididymal sperm and testicular sperm are only suitable for ICSI. Due to numerous favourable reports of oocyte cryopreservation, thaw, fertilization, embryo development, establishment of pregnancies and deliveries of babies, American Society for Reproductive Medicine has removed experimental label from oocyte cryopreservation; however, the ovarian tissue and whole ovary cryopreservation are still considered experimental [4] [5].

In many instances the cancer may not allow enough time to get results for communicable diseases before cryopreservation and the decision to cryopreserve sperm, oocytes, embryos or gonadal tissue have to be made immediately. It is, therefore, highly recommended that the specimens are stored in closed systems to avoid cross contamination in storage. Alternatively, dedicated dry shippers can be arranged for exclusive use of such high risk specimens. This article focuses on various options available to those females and males who are at risk of losing fertility due to surgery, chemotherapy, radiation or any other fertility threat.

\section{Fertility Preservation Counseling}

Several studies indicate that fertility issues are very important to younger women with cancer. Studies from Canada, Sweden and US showed that $50 \%$ - $60 \%$ of women below 40 years with cancers expressed a wish to have one or more children in the future. An early referral to a fertility specialist who can provide clear advice can help the patients make an informed decision about fertility preservation [2]. The fertility-related general communication is not sufficient, and the patients require more individualized and specific information about their fertility preservation choices.

American Society of Clinical Oncology recommends that as part of education and informed consent before cancer therapy, oncologists should address the possibility of infertility with patients and be prepared to discuss possible fertility preservation options or refer patients to reproductive specialists offering fertility preservation [6]. The mental health professionals and genetic counselors be available to counsel the patient and support them in decision-making. Genetic counselors are required to discuss any potential risks of transmission of the disease to the resulting offspring and to provide information on available genetic testing in heritable diseases [7]

\section{Fertility Cryopreservation Options for Male}

Most common and clinically applicable fertility preservation options for men and adolescent boys are summarised (Table 1) and explained under each option.

\subsection{Cryopreservation of Sperm}

Sperm cryopreservation is one of the most well-established techniques in assisted reproductive technology laboratories worldwide. It is a useful tool for fertility preservation in adolescent and adult males. The sperm sample can be obtained by ejaculation (masturbation, vibratory ejaculation/electroejaculation), percutaneous epididymal sperm aspiration (PESA) or testicular sperm extraction (TESE).

After cancer treatment, up to $32 \%(\mathrm{n}=11 / 34)$ of the patients had significantly worse semen analysis findings, including four who suffered from azoospermia [8], therefore, sperm cryopreservation is an invaluable tool for preserving the reproductive potential of such male patients and every effort should be made to refer these patients for sperm cryopreservation before proceeding to their gonadotoxic treatment, even if their sperm quality is 
Table 1. Fertility preservation options for male cancer patients.

\begin{tabular}{|c|c|c|}
\hline Option & Technique & Suitable Candidate \\
\hline \multirow[t]{4}{*}{ Semen cryoprservation } & Ejaculation & Adult/adolescent males capable of ejaculateion \\
\hline & Urine analysis post ejaculation & Retrograde ejaculation cases \\
\hline & Electroejaculation/penile vibratory stimulation & Adolescent or adult males unable to ejaculate \\
\hline & PESA & Obstructive azoospermia \\
\hline $\begin{array}{l}\text { Testicular tissue } \\
\text { cryopreservation }\end{array}$ & TESE or micro-TESE & $\begin{array}{l}\text { Failure to find sperm in the ejaculate or } \\
\text { PESA or for prepubertal boys }\end{array}$ \\
\hline $\begin{array}{l}\text { Testicular protection or } \\
\text { transposition }\end{array}$ & Lead covers or surgery & If therapy is irradiation only \\
\hline
\end{tabular}

suboptimal. With the advent and successful clinical use of ICSI, only one sperm per egg is required. No matter how poor the sperm concentration and motility are, it is possible in majority of cases to find enough sperm for ICSI for successful fertilization and embryo development. It is a simple and effective way of preserving fertility potential of adult males and pubertal boys undergoing gonadotoxic treatment. Successful sperm cryopreservation has been reported in adolescent patients from the age of 13 years [1].

Ejaculation is the most common way of obtaining sperm. In cases of failure to find sperm in the ejaculate, search for spermatozoa in post ejaculation urine sample to rule out retrograde ejaculation is recommended. Other methods described for retrieval of spermatozoa in adolescents include penile vibratory stimulation and electro-ejaculation [1]. The basic principles and methods of sperm cryopreservation for testicular, epididymal, and ejaculated sperm are similar and involve the use of glycerol as a cryoprotectant [9].

The procedures of freezing and thawing of cryopreserved sperm samples have a negative impact on sperm quality and may impact successful assisted reproduction. Therefore, cryopreservation of at least three semen samples with an abstinence period of 48 hours in between samples is recommended [1]. Men with testicular germ cell tumors have a sperm survival rate of only $44.8 \%$ and the lowest odds of having a post thaw total motile count above 5 million for intra uterine insemination. Therefore, men with testicular cancer with seminoma histology or lower fresh total motile count ( $<25-30$ million) should consider preserving additional vials (15 or more) before oncologic treatment [10] if sperm are intended to be used for intra uterine insemination. However, in situations of severe time constraint, cryopreservation of only one ejaculate in multiple vials is recommended so that the sperm can be used for ICSI which requires only one sperm per egg retrieved. Figure 1 shows different sources of sperm for cryopreservation.

\subsection{Cryopreservation of Testicular Tissue}

Fertility preservation technique in males varies depending on the age and nature of the treatment. Post-pubertal boys undergoing chemotherapy can have semen cryopreservation like adults. However, fertility preservation for pre-pubertal boys undergoing chemotherapy implies testicular tissue cryopreservation [11] and must be offered to boys even if maturation of immature germ cells is yet uncertain, for future research may enable fertility restoration. However, in situations like obstructive azoospermia upon failure to find sperm from epididymis or in non-obstructive azoospermia with significantly diminished sperm production final resort is to find and cryopreserve sperm from small pieces of testicular tissue without aid of microscope (TESE) or with aid of microscope (Micro TESE). The later has higher chances to find sperm as it allows for the precise removal of tiny volumes of testicular tissue from areas of active sperm production using a microscope.

\subsection{Testicular Protection or Surgical Repositioning}

Boys or adults undergoing irradiation can have testicular protection or surgical repositioning of the testicle. Shielding of the gonadal area is the standard procedure for reducing scatter radiation to the reproductive organs and to preserve fertility [12]. The extent of radiation damage will depend on the dose, irradiation schedule and field.

\section{Fertility Cryopreservation Options for Female}

Fertility preservation options available to women and adolescent girls are graphically represented in Figure 2 


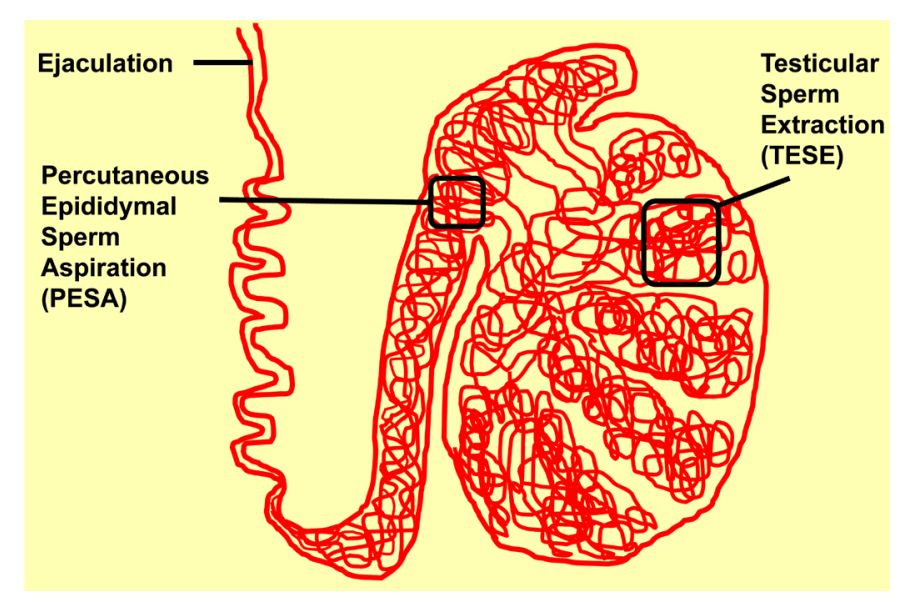

Figure 1. Different sources of male gamete for cryopreservation.

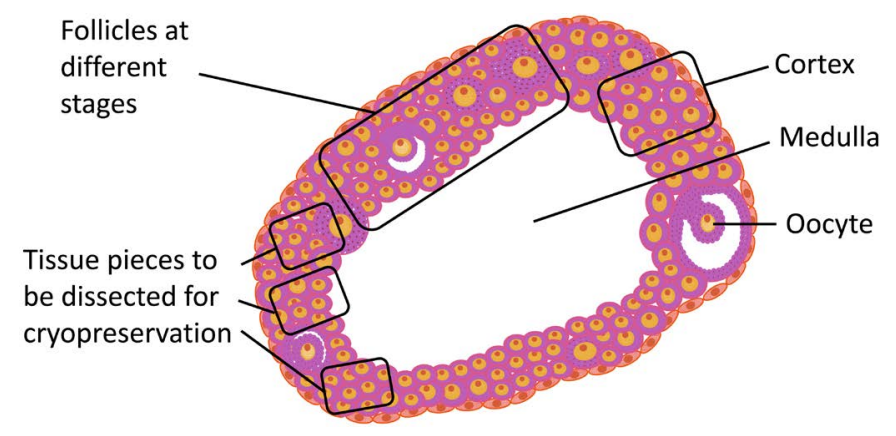

Figure 2. Human ovary showing different parts for cryopreservation.

and listed in Table 2.

\subsection{Cryopreservation of Oocytes}

Oocyte cryopreservation allows women to maintain reproductive autonomy and is recommended for unmarried women, women with no male partner, and for those who do not wish to preserve embryos because of religious or ethical concerns [13]. It may also be an option for adolescent girls in selected cases. For example in 2010, a 14-year-old adolescent with Turner syndrome mosaicism and impending premature ovarian failure was interested in undergoing hormonal stimulation and oocyte freezing instead of ovarian tissue cryopreservation, which is usually the preferred option for children [14]. Post-thaw survival, in vitro fertilization and pregnancy rates of cryopreserved oocytes have increased significantly over the past few years [15]. The vitrification is current method of choice when cryopreserving MII oocytes [16].

Oocyte cryopreservation is not possible in prepubertal girls. Further, it requires ovarian stimulation which causes delay in cancer treatment. It also generates a limited number of oocytes which restricts the number of attempts for pregnancy.

\subsection{Cryopreservation of Embryos}

Cryopreservation of embryos is an established technology. Vitrification is predominantly used. Early cleavage stage embryos can be cryopreserved with equal success using slow cooling and vitrification. However, successful blastocyst cryopreservation may be more consistently achieved with vitrification. The post-thaw survival rates after vitrification are almost 100 per cent and the pregnancy rates are similar or better than those achieved after fresh embryo transfer.

Embryo cryopreservation requires the patient to undergo ovarian stimulation and in vitro fertilization. Since a sperm sample is required, it can only be used in married or patients with male partner or willing to use donor sperm. The other limitations are that it delays cancer treatment. It is not recommended for patients suffering 
Table 2. Fertility preservation options for females.

\begin{tabular}{|c|c|c|}
\hline Option & Technique & Suitable Situation \\
\hline $\begin{array}{l}\text { Oocyte } \\
\text { cryopreservation }\end{array}$ & $\begin{array}{l}\text { Usually requires ovarian } \\
\text { stimulation and oocyte collection }\end{array}$ & $\begin{array}{l}\text { - When enough time is available before cancer treatment of } \\
\text { unmarried women/adolescent girls for extraction of oocytes } \\
\text { - Cancer is not aggravated by stimulation hormones }\end{array}$ \\
\hline Embryo cryopreservation & Ovarian stimulation and IVF & $\begin{array}{l}\text { - Women with male partner or using donor sperm } \\
\text { - When enough time is available before Cancer treatment } \\
\text { - Cancer is not aggravated by stimulation hormones }\end{array}$ \\
\hline $\begin{array}{l}\text { Ovarian tissue } \\
\text { cryopreservation }\end{array}$ & Surgical removal of ovarian tissue & $\begin{array}{l}\text { - Urgent cancer therapy is required } \\
\text { - Prepubertal girls } \\
\text { - Hormone sensitive cancers }\end{array}$ \\
\hline $\begin{array}{l}\text { Whole ovary } \\
\text { cryopreservation }\end{array}$ & $\begin{array}{l}\text { Surgical removal of } \\
\text { the whole ovary }\end{array}$ & - Same as mentioned for ovarian tissue cryopreservation \\
\hline $\begin{array}{l}\text { Combination of ovarian } \\
\text { tissue and oocyte/embryo } \\
\text { cryopreservation }\end{array}$ & $\begin{array}{l}\text { Surgery followed by ovarian } \\
\text { stimulation and } \\
\text { IVF/oocyte freezing }\end{array}$ & $\begin{array}{l}\text { - Urgent cancer therapy is required } \\
\text { - Cancer is not aggravated by stimulation hormones }\end{array}$ \\
\hline
\end{tabular}

from estrogen-sensitive tumors and raises ethical, legal and religious implications for disposal of embryos in case patient dies. It can't be used in pre-pubertal patients [7]. In many countries it is now mandatory to have the couple sign informed embryo cryopreservation consent to specify handling of these embryos.

\subsection{Cryopreservation of Ovarian Tissue}

Ovarian tissue cryopreservation and re-implantation is an option to preserve fertility in patient who has to undergo chemotherapy and/or radiotherapy for aggressive malignancies and there is not enough time to allow ovulation induction, oocyte retrieval and cryopreservation of oocytes/embryos. It is the only option in pre-pubertal girls or women with hormone-sensitive cancers [4]. The immature oocytes will have to be matured either in vivo or in vitro in order to restore fertility [11]. The first child born from ovarian tissue cryopreservation and transplantation was reported in 2004 by Jacques Donnez in Belgium, to a woman with history of chemotherapy and radiation for Hodgkin's lymphoma after orthotopic transplantation [17]. Since then, many births have been reported. However, the Practice Committee of ASRM still considers ovarian tissue cryopreservation an experimental technique for fertility preservation [4].

It is an efficient option to preserve fertility of children and young adults, however, alternative procedures such as oocyte or embryo cryopreservation should be considered as first options especially for older patients or if there is high risk of neoplastic cells within the ovaries [18].

Obtaining a small volume of cortical tissue that is rich in primordial follicles enables cryopreservation of a large number of oocytes. The ovarian tissue is transported to laboratory on ice and cut into $0.3-2 \mathrm{~mm}$ thick pieces and then cryopreserved. The tissue is transplanted after cancer therapy. The slow-freezing has been used more often; however, vitrification is now gaining popularity [4].

Ovarian tissue cryopreservation has many advantages. It does not delay cancer therapy, avoids risk of ovarian stimulation and does not require partner or donor sperm. It also preserves a larger number of follicles and allows for resumption of ovarian function which generally resumes between 60 and 240 days post-transplant [19]. It is the only technique available for preserving fertility in pre-pubertal girls. Reintroduction of cancer following ovarian tissue transplantation is a major concern.

The frozen cortical tissue can be thawed when the patient is declared cancer free and transplanted onto the patient's ovary (orthotopic transplantation) or other sites (heterotopic transplantation), such as the forearm or the abdominal wall. Autologous orthotopic transplantation allows for the possibility of natural fertilization [20]. With heterotopic transplantation pregnancy can only be achieved by oocyte retrieval and in-vitro fertilization utilizing assisted reproductive technologies. There has been no live birth reported with this technique in human, although restorations of endocrine function, successful oocyte retrieval and fertilization have been possible.

\subsection{Whole Ovary Cryopreservation}

The whole ovary is removed with a large part of vascular pedicle attached [4]. It enables the use of profusion 
equipment to introduce cryoprotectants to all cells of the ovary, remove them on thawing and helps in ovarian transplantation, thereby decreasing the risk of ischemia and poor tissue survival seen after transplantation of cortical fragments. Both slow-freezing and vitrification techniques have been used [21]. One of the challenges is possibility of reintroduction of cancer cells that may remain in medullary tissue [22]. Also, difficulties still exist in cryopreservation of the relatively large ovarian tissue mass.

Eleven women underwent fresh donor ovary transplantation, and 11 underwent cryopreserved ovary autotransplantation in the same centre, with the same surgeon. Recovery of ovarian function and follicle recruitment was assessed and the potential for pregnancy was further investigated over 1-year follow-up. Seventeen babies were born to 11 fresh and eight cryopreserved ovary transplant recipients. The auto-transplantation of cryopreserved ovary tissue yielded results almost identical to fresh transplantation. These grafts can last for a long time despite reduced AMH levels if the donor's ovarian reserve is high. In all cases of cryopreserved autotransplantation, just as in fresh transplants, a robust return of menstrual cycling and normal ovarian function were observed at almost precisely the same time after surgery (4.5 months) in all recipients [23].

\subsection{Combination of Ovarian Tissue and Embryo Cryopreservation}

The use of bilateral ovarian cortex cryopreservation followed by controlled ovarian stimulation and embryo freezing has been investigated [24]. This combined approach does not impair the number or quality of cryopreserved embryos, does not delay oncological treatment and increases fertility preservation potential. This approach does not delay oncological treatment. It may even be proposed to patients without a male partner in association with oocyte vitrification. The authors suggested removal of approximately $20 \%$ of ovarian cortex from each ovary prior to IVF and oocyte/embryo cryopreservation. Two other studies reported little different approaches [25] [26]. Theoretically, ovarian stimulation induces high estradiol levels that could be deleterious to hormone-sensitive cancers like breast cancer. Aromatase inhibitors like letrozole can be used to minimize oestrogen exposure in breast cancer patients. GnRH agonist trigger improves outcomes by increasing the yield of mature oocytes and embryos in aromatase inhibitor cycles and also decreases the post-trigger oestradiol exposure as well as ovarian hyper stimulation syndrome risks in women with breast cancer [27] [28]. Classical ovarian stimulation in non-metastatic breast cancer and lymph node-negative breast cancer was used in the other study [24] as the authors did not see any evidence that 4 - 5 days of high estradiol levels may be deleterious for patients or impact their survival.

\subsection{Ovarian Transposition}

Ovaries can be surgically moved outside the irradiation field. It consists of releasing the ovary from its pelvic attachments and placing it behind the uterus or any other suitable place. This strategy is useful in cervical cancer [29].

\subsection{Ovarian Follicle Culture}

It is intended to be an alternative to ovarian tissue transplantation to avoid risk of reintroducing cancer. The end product of this in vitro culture system is mature oocytes from primordial and primary follicles. Much work still is required to make this approach clinically applicable [29].

\section{Post-Thaw Assessment of Cryopreserved Specimens}

It is of paramount importance that adequate quality control and quality assurance methods are applied for collection, transportation, processing and cryopreservation to consistently achieve desirable outcome from the cryopreserved material. For sperm samples, post-thaw motility assessment from a test vial of about 200 micro litres or even less is recommended. This also helps in deciding the number of samples to be cryopreserved before initiating cancer treatment. In some instances, advanced techniques of sperm viability assessment like hypo-osmotic swelling test [30] may have to be used to pick viable sperm for ICSI.

\section{Future Technologies}

For men and prepubertal boys, spermatogonial stem cell transfer holds promise if the risk of reintroduction of 
cancer can be eliminated by technologies such as purging the tissue and germ cell culture [31]. The derivation of male gametes from stem cells also holds much promise; however, data are only available in animals, and the use of this method in human beings is probably many years away [32].

For women and girls, unravelling the complex mechanisms of activation and suppression of follicle growth will expand the care of women diagnosed with cancer. In addition, pharmacological protection against gonadotoxic agents, in-vitro follicle growth and follicle transplantation are likely to be optimised and established within the next decade [33]). Further research to minimize damage from cancer therapy to male or female gametes or reproductive stem cells is needed.

\section{Conclusion}

There has been significant advancement in fertility preservation options available to cancer patients. It is essential that individuals under threat of fertility loss should be offered appropriate fertility preservation option. An integrated approach by oncologists, urologists, surgeons, gynecologists, pediatricians, fertility preservation specialists and counselors is needed to make use of these options to improve quality of life for cancer survivors.

\section{References}

[1] Rodriguez-Wallberg, K.A. and Oktay, K. (2014) Fertility Preservation during Cancer Treatment: Clinical Guidelines. Cancer Management and Research, 6, 105-117. http://dx.doi.org/10.2147/CMAR.S32380

[2] Hoeg, D., Schmidt, L. and Macklon, K.T. (2015) Cancer and Fertility-A Qualitative Pilot Study of Young Female Cancer Patients' Experiences with Fertility Counseling and Fertility Preservation. Austin Journal of Reproductive Medicine \& Infertility, 2, 1005.

[3] Dursun, P., Doğan, N.U. and Ayhan, A. (2014) Oncofertility for Gynecologic and Non-Gynecologic Cancers: Fertility Sparing in Young Women of Reproductive Age. Critical Reviews in Oncology/Hematology, 92, 258-267. http://dx.doi.org/10.1016/j.critrevonc.2014.07.001

[4] Practice Committee of the American Society for Reproductive Medicine (2014) Ovarian Tissue Cryopreservation: A Committee Opinion. Fertility and Sterility, 101, 1237-1243. http://dx.doi.org/10.1016/j.fertnstert.2014.02.052

[5] ACOG: Committee Opinion No. 584 (2014) Oocyte Cryopreservation. Obstetrics \& Gynecology, 123, $221-222$. http://dx.doi.org/10.1097/01.AOG.0000441355.66434.6d

[6] Lee, S.J., Schover, L.R., Partridge, A.H., Patrizio, P., Wallace, W.H., Hagerty, K., et al. (2006) American Society of Clinical Oncology Recommendations on Fertility Preservation in Cancer Patients. Journal of Clinical Oncology, 24, 2917-2931. http://dx.doi.org/10.1200/JCO.2006.06.5888

[7] Mahajan, N. (2015) Fertility Preservation in Female Cancer Patients: An Overview. Journal of Human Reproductive Sciences, 8, 3-13. http://dx.doi.org/10.4103/0974-1208.153119

[8] Chung, J.P., Haines, C.J. and Kong, G.W. (2013) Sperm Cryopreservation for Chinese Male Cancer Patients: A 17Year Retrospective Analysis in an Assisted Reproductive Unit in Hong Kong. Hong Kong Medical Journal, 19, 525530. http://dx.doi.org/10.12809/hkmj134055

[9] Gangrade, B.K. (2013) Cryopreservation of Testicular and Epididymal Sperm: Techniques and Clinical Outcomes of Assisted Conception. Clinics, 68, 131-140. http://dx.doi.org/10.6061/clinics/2013(Sup01)15

[10] Hotaling, J.M., Pate, D.P., Vendryes, C., Lopushnyan, N.A., Presson, A.P., Zhan,g C., Muller, C.H. and Walsh, T.J. (2015) Predictors of Sperm Recovery after Cryopreservation in Testicular Cancer. Asian Journal of Andrology. [Epub Ahead of Print] http://www.ajandrology.com/preprintarticle.asp?id=155535 http://dx.doi.org/10.4103/1008-682X.155535

[11] de Lambert, G., Poirot, C., Guérin, F., Brugières, L. and Martelli, H. (2015) Preservation of Fertility in Children with Cancer. Bulletin du Cancer, 102, 436-442. (In French) http://dx.doi.org/10.1016/j.bulcan.2015.02.015

[12] Rodriguez-Wallberg, K.A. and Oktay, K. (2014) Fertility Preservation during Cancer Treatment: Clinical Guidelines. Cancer Management and Research, 6, 105-117.

[13] Rodriguez-Wallberg, K.A. and Oktay, K. (2012) Recent Advances in Oocyte and Ovarian Tissue Cryopreservation and Transplantation. Best Practice \& Research Clinical Obstetrics \& Gynaecology, 26, 391-405. http://dx.doi.org/10.1016/j.bpobgyn.2012.01.001

[14] Oktay, K., Rodriguez-Wallberg, K.A. and Sahin, G. (2010) Fertility Preservation by Ovarian Stimulation and Oocyte Cryopreservation in a 14-Year-Old Adolescent with Turner Syndrome Mosaicism and Impending Premature Ovarian Failure. Fertility and Sterility, 94, 753.e15-753.e19. http://dx.doi.org/10.1016/j.fertnstert.2010.01.044

[15] Rienzi, L., Romano, S., Albricci, L., Maggiulli, R., Capalbo, A., Baroni, E., et al. (2010) Embryo Development of 
Fresh "versus" Vitrified Metaphase II Oocytes after ICSI: A Prospective Randomized Sibling-Oocyte Study. Human Reproduction, 25, 66-73. http://dx.doi.org/10.1093/humrep/dep346

[16] Edgar, D.H. and Gook, D.A. (2012) A Critical Appraisal of Cryopreservation (Slow Cooling versus Vitrification) of Human Oocytes and Embryos. Human Reproduction Update, 18, 536-554. http://dx.doi.org/10.1093/humupd/dms016

[17] Donnez, J., Dolmans, M.M., Demylle, D., Jadoul, P., Pirard, C., Squifflet, J., et al. (2004) Livebirth after Orthotopic Transplantation of Cryopreserved Ovarian Tissue. Lancet, 364, 1405-1410. http://dx.doi.org/10.1016/S0140-6736(04)17222-X

[18] Imbert, R., Moffa, F., Tsepelidis, S., Simon, P., Delbaere, A., Devreker, F., Dechene, J., Ferster, A., Veys, I., Fastrez, M., Englert, Y. and Demeestere, I. (2014) Safety and Usefulness of Cryopreservation of Ovarian Tissue to Preserve Fertility: A 12-Year Retrospective Analysis. Human Reproduction, 29, 1931-1940. http://dx.doi.org/10.1093/humrep/deu158

[19] Kim, S.S. (2012) Assessment of Long Term Endocrine Function after Transplantation of Frozen-Thawed Human Ovarian Tissue to the Heterotopic Site: 10 Year Longitudinal Follow-Up Study. Journal of Assisted Reproduction and Genetics, 29, 489-493. http://dx.doi.org/10.1007/s10815-012-9757-3

[20] Gunasheela, D. and Gunasheela, S. (2014) Strategies for Fertility Preservation in Young Patients with Cancer: A Comprehensive Approach. Indian Journal of Surgical Oncology, 5, 17-29. http://dx.doi.org/10.1007/s13193-014-0291-x

[21] Bedaiwy, M.A., Hussein, M.R., Biscotti, C. and Falcone, T. (2006) Cryopreservation of Intact Human Ovary with Its Vascular Pedicle. Human Reproduction, 21, 3258-3269. http://dx.doi.org/10.1093/humrep/del227

[22] Kim, S.S. (2010) Time to Rethink: Ovarian Tissue Transplantation versus Whole Ovary Transplantation. Reproductive BioMedicine Online, 20, 171-174. http://dx.doi.org/10.1016/j.rbmo.2009.11.019

[23] Silber, S., Pineda, J., Lenahan, K., DeRosa, M. and Melnick, J. (2015) Fresh and Cryopreserved Ovary Transplantation and Resting Follicle Recruitment. Reproductive BioMedicine Online, 30, 643-650. http://dx.doi.org/10.1016/j.rbmo.2015.02.010

[24] Dolmans, M., Marotta, M., Pirard, C., Donnez, J. and Donnez, O. (2014) Ovarian Tissue Cryopreservation Followed by Controlled Ovarian Stimulation and Pick-Up of Mature Oocytes Does Not Impair the Number or Quality of Retrieved Oocytes. Journal of Ovarian Research, 7, 80. http://dx.doi.org/10.1186/s13048-014-0080-8

[25] Huober-Zeeb, C., Lawrenz, B., Popovici, R.M., Strowitzki, T., Germeyer, A., Stute, P. and von Wolff, M. (2011) Improving Fertility Preservation in Cancer: Ovarian Tissue Cryobanking Followed by Ovarian Stimulation Can Be Efficiently Combined. Fertility and Sterility, 95, 342-344. http://dx.doi.org/10.1016/j.fertnstert.2010.07.1074

[26] Dittrich, R., Lotz, L., Mueller, A., Hoffmann, I., Wachter, D.L., Amann, K.U., Beckmann, M.W. and Hildebrandt, T. (2013) Oncofertility: Combination of Ovarian Stimulation with Subsequent Ovarian Tissue Extraction on the Day of Oocyte Retrieval. Reproductive Biology and Endocrinology, 11, 19. http://dx.doi.org/10.1186/1477-7827-11-19

[27] Oktay, K., Türkçüoğlu, I. and Rodriguez-Wallberg, K.A. (2010) GnRH Agonist Trigger for Women with Breast Cancer undergoing Fertility Preservation by Aromatase Inhibitor/FSH Stimulation. Reproductive BioMedicine Online, 20, 783-788. http://dx.doi.org/10.1016/j.rbmo.2010.03.004

[28] Reddy, J., Turan, V., Bedoschi, G., Moy, F. and Oktay, K. (2014) Triggering Final Oocyte Maturation with Gonadotropin-Releasing Hormone Agonist (GnRHa) versus Human Chorionic Gonadotropin (hCG) in Breast Cancer Patients Undergoing Fertility Preservation: An Extended Experience. Journal of Assisted Reproduction and Genetics, 31, $927-$ 932. http://dx.doi.org/10.1007/s10815-014-0248-6

[29] González, C., Boada, M., Devesa, M. and Veiga, A. (2012) Concise Review: Fertility Preservation: An Update. Stem Cells Translational Medicine, 1, 668-672. http://dx.doi.org/10.5966/sctm.2012-0076

[30] Partyka, A., Nizanski, W. and Ochota, M. (2012) Methods of Assessment of Cryopreserved Semen. In: Katkov, I.I., Ed., Current Frontiers in Cryobiology, InTech, Rijeka, 547-575. http://dx.doi.org/10.5772/33565

[31] Gosden, R.G. (2013) Memoir of Fertility Preservation. In: Kim, S.S., Ed., Oocyte Biology in Fertility Preservation, Advances in Experimental Medicine and Biology, Vol. 761, Springer, New York, 85-94. http://dx.doi.org/10.1007/978-1-4614-8214-7_7

[32] Tournaye, H., Dohle, G. and Barratt, C.L.R. (2014) Fertility Preservation 1: Fertility Preservation in Men with Cancer. Lancet, 384, 1295-1301. http://dx.doi.org/10.1016/S0140-6736(14)60495-5

[33] DeVos, M., Smitz, J. and Woodruff, T. (2014) Fertility Preservation 2: Fertility Preservation in Women with Cancer. Lancet, 384, 1302-1310. http://dx.doi.org/10.1016/S0140-6736(14)60834-5 